\title{
Tituli loquentes en ibérico: una aproximación desde el análisis interno y la epigrafía comparada*
}

\author{
Noemí Moncunill \\ Universitat de Barcelona \\ nmoncunill@ub.edu \\ ORCID iD: https://orcid.org/0000-0002-5568-3377 \\ Javier Velaza \\ Universitat de Barcelona \\ velaza@ub.edu \\ ORCID iD: https://orcid.org/0000-0002-5811-3345
}

\section{Tituli loquentes in Iberian Language: An Approach from Internal Analysis and Comparative Epigraphy}

\begin{abstract}
Este artículo analiza una serie de inscripciones ibéricas en las que aparece el elemento -ḿi / -nai, para el que defendemos una interpretación o bien como pronombre personal de primera persona o bien como primera persona del verbo copulativo. De ello se desprende que un conjunto de inscripciones ibéricas, especialmente sobre cerámica, y en menor medida sobre plomo y piedra, podrían interpretarse como $t i$ tuli loquentes y, en consecuencia, responderían a una
\end{abstract}

The present paper analyses a series of Iberian inscriptions in which the element -ḿi / -nai can be identified. We propose to interpret it either as the first-person personal pronoun or as the firstperson copulative verb. It follows that a large number of Iberian inscriptions, especially on pottery, and to a lesser extent on lead and stone, can be interpreted as tituli loquentes and, consequently, would respond to a well-known epigraphic

${ }^{1}$ Este trabajo se inscribe dentro de los proyectos «Estudio paleográfico, lingüístico y funcional del corpus epigráfico ibérico» (PID2019-106606GB-C33), «Escrito para los dioses. Escritura y ritualidad en la Península Ibérica antigua» (PID2019-105650GB-I00) y en el Grup de Recerca Consolidat LITTERA (2017SGR241). Las inscripciones ibéricas son citadas según la Base de Datos Hesperia (BDH); para su transcripción hemos seguido las siguientes convenciones: negrita para los textos en signario ibérico, negrita y cursiva para los textos en signario ibérico dual, cursiva para los textos en grecoibérico, mayúsculas para los textos en alfabeto latino, caracteres griegos para las inscripciones en alfabeto griego. Queremos agradecer a Joan Ferrer sus valiosas sugerencias al texto. 
tipología epigráfica bien conocida entre las culturas escritas del Mediterráneo occidental. El artículo indaga asimismo en los posibles modelos exógenos concretos que habrían podido motivar la adopción de este hábito, decantándose por la influencia de la epigrafía griega como motor principal.

Palabras clave: lengua ibérica; epigrafía paleohispánica; tituli loquentes; epigrafía comparada. typology among the written cultures of the western Mediterranean. The article also investigates the possible exogenous models that could have motivated the adoption of this habit, opting for the influence of Greek epigraphy as the main driving factor.

Key words: Iberian language; palaeohispanic epigraphy; tituli loquentes; comparative epigraphy.

Cómo citar este artículo / Citation: Moncunill, Noemí y Velaza, Javier (2021): «Tituli loquentes en ibérico: una aproximación desde el análisis interno y la epigrafía comparada», Emerita 89 (2), pp. 309-339.

\section{Introducción}

Los tituli loquentes son un tipo epigráfico muy común en las distintas culturas escriturarias del Mediterráneo Occidental, sobre todo durante los primeros estadios de su desarrollo ${ }^{1}$. Tipológicamente se caracterizan por ser inscripciones de carácter formular redactadas en primera persona, creando así la ficción estilística de que es el objeto mismo quien se dirige al lector, en lo que se ha considerado una especie de autorrepresentación del soporte inscrito (Norden 1939, p. 265) que resulta especialmente productiva en el contexto de las ofrendas cultuales ${ }^{2}$.

Tanto en el mundo helénico (Burzachechi 1962; Lazzarini 1973-1974) como en la península itálica (Norden 1939; Agostiniani 1982; Crawford 2011) existen numerosos testimonios de esta práctica, con ejemplares que remontan respectivamente a los siglos VIII y VII a. $\mathrm{C}^{3}$. Aunque se trata, por

${ }^{1}$ Para el estudio de este tipo de inscripciones en Grecia e Italia son imprescindibles Burzachechi 1962 y Agostiniani 1982, donde se considera Norden 1939 el primer trabajo en llamar la atención sobre las similitudes entre los tituli loquentes griegos, latinos, etruscos, oscos etc., asumiendo así que se trataba de un fenómeno de transferencia cultural que debía ser estudiado globalmente. Algunos trabajos más recientes son Carraro 2007; Maras 2015; Cinti 2019.

2 Véase Poccetti 2009 para valorar el uso frecuente de inscripciones parlantes en los paradigmas formulares votivos empleados en las lenguas epicóricas de Italia; Colonna 1990, en particular para los ejemplos en etrusco (en especial p. 877 ss. para los formularios parlantes); y Lazzarini 1976 para las fórmulas votivas en griego arcaico.

${ }^{3}$ Uno de los testimonios más tempranos en griego podría ser la denominada «copa de Néstor», de ca. 720 a. C., y que se considera uno de los textos en griego alfabético más anti- 
consiguiente, de un uso bien consolidado en Occidente desde época arcaica ${ }^{4}$ - hecho que denota, como veremos a continuación, la circulación de determinados modelos culturales asociados a la práctica de la escritura-, su uso seguirá vigente durante toda la Antigüedad, e incluso hasta bien entrada la Edad Media (Benucci y Foladore 2008).

Como demostró Agostiniani en su célebre trabajo sobre las inscripciones parlantes de la Italia antigua, la difusión de este hábito deriva en última instancia de un modelo griego ${ }^{5}$ y resulta especialmente ilustrativa para detectar fenómenos de interferencia entre las distintas tradiciones epigráficas (Agostiniani 1982, p. 267 ss.), y es que los ejemplos no se ciñen en este ámbito únicamente a las inscripciones en latín — recuérdese, sin ir más lejos, la fíbula de Praeneste o el vaso Duenos - sino que atañen prácticamente a la totalidad de las lenguas y escrituras del área: venético, etrusco, falisco, osco, umbro, sudpiceno, mesapio y élimo. Coincidimos asimismo con la tesis de partida de este trabajo (Agostiniani 1982, p. 269) de que la aparición de este esquema repetitivo en prácticamente todas las lenguas paleoitálicas no puede ser explicada simplemente como una coincidencia debida a cuestiones de tipo antropológico y psicológico propias de las civilizaciones antiguas, sino que ha de obedecer a procesos de derivación y de imitación. A nuestro modo de ver, esta perspectiva debe ser aplicada también al estudio de los tituli loquentes en otros puntos del Mediterráneo occidental, en particular la península ibérica, donde esta tradición pudo haber tenido, como defenderemos en este trabajo, una notable vitalidad en el ámbito ibérico, cuya cultura epigráfica estuvo en un primer momento profundamente marcada por el contacto con

\footnotetext{
guo, aunque la restitución del texto es problemática. Para Burzachechi (1962, p. 28) el vaso parlante más antiguo en griego es la «copa de Korakos», también del s. VIII a. C.

${ }^{4}$ Además de los numerosos testimonios epigráficos, sobre la antigüedad de este fenómeno

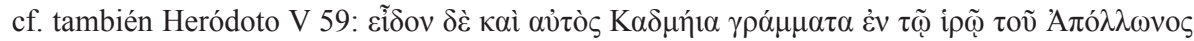

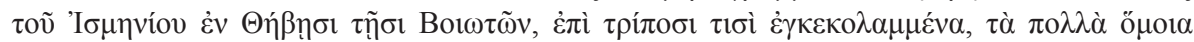

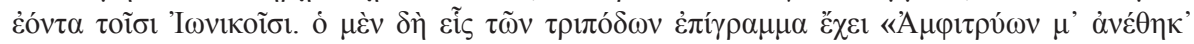

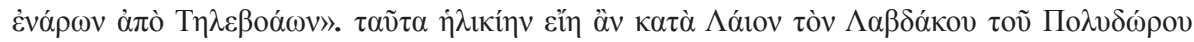

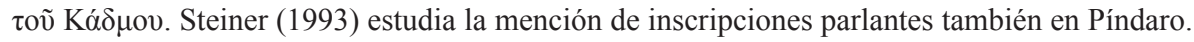

${ }^{5}$ Wachter (2010) aporta algunas reflexiones sobre los posibles orígenes de esta tradición en Grecia.
} 
los griegos, especialmente los foceos ${ }^{6}$, e incluso, en determinadas regiones, en particular el Languedoc, también con los etruscos.

\section{La existencia de tituli loquentes en ibérico}

En la península ibérica existen también inscripciones que encajan en la categoría de tituli loquentes. Las más antiguas de ellas son inscripciones en griego datables en el siglo VI a. C.: portan textos con ofrendas cultuales (cf.

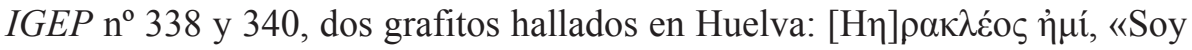
de Heracles» y [---]Níkn $\varepsilon i[\mu \mathrm{l}]^{7}$, «soy de Nike») o simplemente presentan el nombre del vaso introducido por el verbo copulativo en primera persona (así en $I G E P \mathrm{n}^{\circ} 388$, un dipinto sobre cerámica ática interpretado como una firma

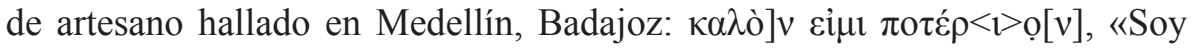
un bonito vaso») $)^{8}$. También del s. VI a. C. es un grafito métrico de Empúries con una dedicación lúdica de carácter probablemente simposíaco (IGEP $\mathrm{n}^{\circ}$

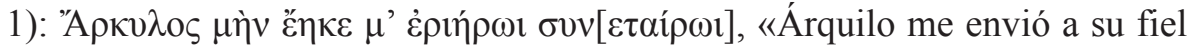
com[pañero]». Estos ejemplos son relevantes, puesto que muestran claramente la circulación de este hábito en la península ibérica en un horizonte epigráfico antiguo, momento en el que es posible detectar, por lo demás, una notable variedad de usos y contextos (votivo, artesanal, lúdico).

En la vecina Galia encontramos igualmente algún caso de vaso parlante inscrito en griego: así, por ejemplo, algunas copas en campaniense A (s. II-I a. C.) halladas en el santuario de Aristeo en la península de Giens, y que portan de nuevo textos de carácter cultual (IGF 68-2 y 68-8) ${ }^{9}$. Sin embargo, el fenómeno más interesante que nos brinda este territorio es la translación de esta práctica a la epigrafía indígena, esto es, al galo, como lo muestra un grafito de la misma época en escritura galo-griega procedente del oppidum

${ }^{6}$ Para las características de la cultura epigráfica en las colonias jonias de Occidente, véase De Hoz (en prensa).

${ }^{7}$ Para la discusión sobre la lectura y restitución de este epígrafe, véase IGEP, pp. 350-351.

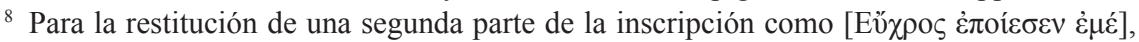
véase $I G E P$, p. 415. Para las fórmulas de los vasos parlantes griegos, Lazzarini 1973-1974, p. $343 \mathrm{n}^{\circ} 3$, 4b. Bellelli y Benelli (2009 [2010]) proporcionan, a su vez, una actualización sobre la costumbre de explicitar el nombre del vaso también en etrusco.

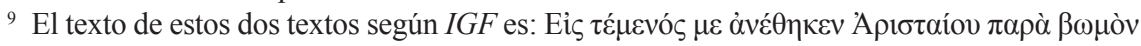

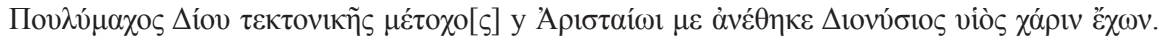


de La Cloche (Les Pennes-Mirabeau), al noroeste de Marsella (RIG I G-13). El texto, esgrafiado en la pared externa del cuenco, reza ЕСКЕГГО $А$ АТ ANIATEIOC IMMI, y podría traducirse por «Soy propiedad inalienable de Eskengolatios».

La tradición de marcar los vasos con inscripciones parlantes continuará igualmente viva en estas zonas avanzada la época romana, tal como se desprende de algunos grafitos latinos hallados tanto en Hispania como en el sur de la Galia (así, p. ej., en el conjunto de Paretstortes [Claustres 1958; Abélanet 1997] o en Mas Sauvy [Moncunill y Bénézet 2018]), ejemplos que muestran cómo en este periodo la funcionalidad religioso-votiva parece desdibujarse en beneficio de un uso claramente lúdico asociado a la comensalidad. También de un carácter claramente jocoso son las inscripciones parlantes que portan algunas de las fusayolas galo-romanas, escritas unas veces en galo, otras en latín, con mensajes que han sido interpretados con un doble sentido erótico (Thüry 1994; Feugère 2004, p. 63): así, por ejemplo, IMPLE ME SIC VERSA ME (CIL XIII 10 019.17) o AVE DOMINA SITIIO (ILTG 524), en las que se juega con la ambigüedad de si es propiamente el objeto quien habla o su destinataria.

Los casos que acabamos de evocar muestran la difusión de las inscripciones parlantes más allá de la península itálica y de Grecia y su penetración hasta la península ibérica ya en el s. VI a. C. Esto nos brinda un marco de interpretación suficientemente amplio para otro de los conjuntos de este territorio que también podría encajar en la tipología de los tituli loquentes: son las más de 100 inscripciones ibéricas sobre diferentes tipos de soportes que presentan el elemento -ḿi. Ya M. Gómez Moreno (1945), considerando la similitud de este segmento con el vasco $n i$ 'yo' ${ }^{10}$, propuso interpretarlo como el pronombre singular de primera persona (debe destacarse, sin embargo, que, tal como veremos más adelante, el valor fonético exacto de la nasal ibérica convencionalmente transcrita con un diacrítico, ḿ, es todavía incierto, aunque, teniendo en cuenta que su notación en grecoibérico parece ser -nai, es muy probable que se tratara de una nasal vocalizada o de una vocal nasalizada). La propuesta de Gómez Moreno ha sido aceptada o tomada en consideración por algunos estudiosos (Tovar 1954, p. 227; Michelena 1961, p. 19; Siles 1985, p. 266; MLH III.1; Ferrer 2006, pp. $148-150$ y 2008, p. 267;

\footnotetext{
${ }^{10}$ Para el estado de la cuestión sobre la relación entre el ibérico y el vasco, véase Orduña 2019.
} 
Moncunill 2017, pp. 144-146), pero implícitamente rebatida por otros, que han sugerido opciones alternativas. En realidad, las hipótesis de interpretación de esta palabra o morfo han sido muy variadas, pero las que en la actualidad siguen recibiendo un apoyo más amplio son:

1. que -ḿi sea el verbo copulativo en tercera o primera persona singular ( $M L H$ III.1 §534.2; Rodríguez Ramos 2005, p. 53), en este segundo caso tal vez en relación con el vasco naiz 'soy' (Rodríguez Ramos 2004, p. 298; 2005, p. 98);

2. que se trate de un demostrativo o deíctico (MLH III.1 $\$ 534.3$; de Hoz 2001, p. 342 ss. y 2011, p. 265; Silgo 2001; Rodríguez Ramos 2005, p. 53; Orduña 2005, p. 305);

3. que se corresponda con algún tipo de posesivo (Silgo 2005, pp. 229-231), o, como sostiene Untermann, con una partícula para expresar posesión, tal vez en cualidad de marca de caso (MLH III.1 $§ 534.1$, aunque sin excluir otras alternativas gramaticales, como las recogidas supra, que podrían servir igualmente para expresar la noción de propiedad).

La posibilidad de que -ḿi/-nai pueda ser una palabra asociada a la primera persona, ya sea como verbo copulativo o pronombre personal (Moncunill y Velaza 2019, p. 366), ha hecho planear la sospecha de que pudieran existir inscripciones parlantes en ibérico (Gómez Moreno 1945; Michelena 1961, p. 19), una posibilidad que el mismo Untermann, aunque con reservas, no descartó para algunos casos concretos (MLH III.1, p. 172) y que otros autores han seguido barajando más recientemente (Rodríguez Ramos 2004, p. 298 y 2005, p. 98; Ferrer 2006, pp. 148-150; Moncunill 2007, p. 242, y 2017; Moncunill y Francès 2017; Velaza 2019, p. 178; Vidal 2019) ${ }^{11}$. Sin embargo, hasta la fecha esta cuestión no ha sido abordada de forma global ni tomando plenamente en consideración la dimensión cultural de este fenómeno, esto es, la influencia directa que los modelos epigráficos griegos pudieron haber ejercido en la adopción de esta práctica, un factor que a nuestro modo de ver resulta crucial para determinar si estas inscripciones ibéricas han de ser, al fin y al cabo, interpretadas como tituli loquentes. En efecto, no nos parece, por ejemplo, un hecho casual que a principios del s. IV a. C. y en la colonia

${ }^{11}$ Otros autores, como de Hoz (2001, p. 343 y 2011, p. 265), expresan, en cambio, reservas sobre la validez de esta interpretación. 
griega de Emporiae, se utilizara precisamente el alfabeto griego para grabar un vaso de cerámica ática con el texto ГОРОТІГINAI (GI.10.15), probablemente una de las primeras inscripciones parlantes en ibérico.

\section{3. - -mí / -nai y el valor fonológico del signo $\boldsymbol{m}$}

El signo ibérico convencionalmente trascrito como ḿ partiendo de su inequívoco valor nasal en celtibérico (Gómez Moreno 1945, p. 278), no tiene, en realidad, una categorización fonética clara en ibérico ${ }^{12}$. Sus contextos de aparición son variados ${ }^{13}$, pero destaca su posición interconsonántica, en secuencias como -nḿk- o incluso nḿkei-, circunstancia que hace suponer que puede actuar como núcleo silábico $\mathrm{y}$, por lo tanto, tener un componente de tipo vocálico, a la vez que nasal.

El problema principal para su definición radica en el hecho de que no solo su adaptación en textos alfabéticos es heterogénea, sino que su notación en silabario ibérico presenta también vacilaciones: así, por ejemplo, mientras que el elemento -ḿi aparece adaptado en grecoibérico como -nai e incluso asimismo en algunos textos en semisilabario ibérico, la palabra keśtańn, habitual del léxico sobre fusayolas, aparece más frecuentemente escrita como kaśtaum o kaśtaun. De forma similar, mientras que el formante antroponímico (n)ḿlbe aparece adaptado al latín como NALBE, el formante (n)ḿbaŕ parece que lo es como VMAR ${ }^{14}$. Existen, por consiguiente, dos notaciones alternativas principales para este carácter en silabario ibérico, ambas documentadas también en las transcripciones en alfabeto griego o latino: la primera equipara ḿ con /na/, mientras que en la segunda este signo se adapta como /un/ o /um/.

En el cuadro de síntesis que presentamos a continuación se recogen los principales datos disponibles para evaluar el posible valor fonológico de este signo. En primer lugar, es posible detectar una alternancia gráfica entre nḿ y ḿ en pares tales como ḿltun / nḿltun; ḿlbe / núlbe; lakum /

12 Para esta cuestión, Siles 1981; Untermann 1984; Tovar 1985; Valeri 1993; Correa 1999; Rodríguez Ramos 2000; Ferrer 2013; Orduña 2017.

${ }_{13}$ Puede encontrarse un análisis detallado de la distribución del signo ḿ en ibérico en Quintanilla 1998, p. 206 ss., Correa 1999, Rodríguez Ramos 2000.

${ }^{14}$ En algunos de estos casos, sin embargo, no puede descartarse totalmente que nos hallemos ante elementos distintos. 
lakunń; ḿbaŕ / nḿbaŕ; ḿkei / nḿkei, etc.; en segundo lugar, a pesar de que la transcripción en los sistemas alfabéticos sugiere que se trata de un carácter con un valor nasal a la vez que vocálico, el timbre de esta vocal no es expresado, como hemos comentado, siempre de la misma forma (pudiendo manifestarse, por lo menos, como /a/, /u/ e incluso /o/); finalmente, el último ejemplo del cuadro muestra cómo la combinación de signos ḿb pudo emplearse también para notar la nasal bilabial, fonema inexistente en ibérico, en préstamos onomásticos, al igual como se emplearon, alternativamente, el dígrafo $\mathbf{n b}$ o simplemente $\mathbf{b}$.

\begin{tabular}{|c|c|c|}
\hline Notación con ḿ & $\begin{array}{l}\text { Notación alternativa en } \\
\text { signario ibérico }\end{array}$ & $\begin{array}{lll}\begin{array}{l}\text { Notación } \\
\text { alfabéticos }\end{array} & \text { en } & \text { sistemas } \\
\end{array}$ \\
\hline atinbin-ḿr $r$ & *atinbin-ar & \\
\hline ]+skeŕbin-ḿr-ḿi[ & *]+skeŕbin-ar-ḿi[ & \\
\hline -ḿi & -nai & $-n a i$ \\
\hline (n)ḿlbe & nalbe & NALBE, N $\alpha \lambda \beta \varepsilon$ \\
\hline (n)ḿltun & naltun & \\
\hline (n)ḿbaŕ & nabaŕ & VMAR \\
\hline keśtaḿn & kaśtaum / kaśtaun & \\
\hline laku(n)ḿn & lakon / lakun / laku & \\
\hline ḿbaske & & Masce \\
\hline
\end{tabular}

Teniendo en cuenta esta casuística, las propuestas principales que se han hecho para describir la naturaleza fonética del signo son las siguientes: que ḿ sea un carácter silábico con el valor de /na/ (Siles 1981), aunque esto difícilmente explicaría su puntual notación también como VM, un e incluso on; que se trate de una nasal con apéndice labial con capacidad silábica $/ \mathrm{m}^{\mathrm{b}} /$ (Tovar 1985, pp. 464 y 467; Correa 1999, p. 392); que se trate de una nasal silábica o vocálica (de Hoz 2001, p. 338; 2011, p. 233); de una vocal nasal o nasalizada /ã/ (Untermann 1998, p. 14; Rodríguez Ramos 2000; Orduña 2017; de Hoz 2001, p. 338); o, finalmente, que sea un signo con distintas realizaciones en función de la variación dialectal o de las distintas escuelas epigráficas, hecho que se evidenciaría en la notación ḿ en contraste con nḿ: la primera notaría una simple combinación de nasal y vocal, mientras que la segunda representaría propiamente una vocal nasal (Ferrer 2013, pp. 164-165). 
Por consiguiente, aunque en el estado actual de la cuestión no es posible determinar el valor preciso de este signo, sí parece seguro que se trata de la combinación de un elemento nasal con otro elemento vocálico cuyo timbre es expresado, sin embargo, de forma diversa. En cualquier caso, para la identificación del elemento -ḿi este hecho reviste una importancia relativa, puesto que su notación parece realizarse de forma bastante sistemática ya sea como -ḿi o como -nai, aunque tampoco es descartable que podamos encontrar esporádicamente algunos casos de notación alternativa como -mi, -ni, o incluso, como se ha propuesto, -ui (cf. GI.15.46, .10.12 y tal vez .15.45, aunque la identificación de este elemento en estos dos casos no es del todo evidente).

\section{Contextos sintácticos del elemento -mí / -nai}

Como hemos avanzado más arriba, las inscripciones ibéricas en las que puede aislarse con seguridad un segmento -ḿi / -nai son proporcionalmente abundantes (120 registros en un corpus total de unas 2.250 inscripciones). Este material nos permite hacer una tipificación de las distintas fórmulas en las que esta palabra interviene; en los cuadros siguientes se esquematizan las principales estructuras con el fin de vislumbrar el valor gramatical y semántico de esta palabra.

Tabla 1: SN + -míi / -nai

\begin{tabular}{|c|c|c|c|c|c|c|}
\hline $\mathrm{N}^{\circ}$ & NP & SNgen & $\begin{array}{l}\text { SN (ref. } \\
\text { objeto) }\end{array}$ & Det. & & Ref. \\
\hline 1.1. & taŕbanikoŕ & & & & -ḿni & CS.01.02 \\
\hline 1.2 . & & il+ti? & baikar & & $-\dot{m} i$ & GI.07.01 \\
\hline 1.3 . & & & kaśtaum & ban & $-\dot{m} i$ & GI.13.07 \\
\hline 1.4 . & & iltiŕbikis-en & seltar & & -ḿi & CS.11.01 \\
\hline 1.5 . & & iltiŕta & śalií & & -nai & Mon.18.4 \\
\hline
\end{tabular}

Tabla 2: SN-ar/-en + -ḿi / -nai + (SN)

\begin{tabular}{|c|c|c|c|c|c|c|}
\hline $\mathrm{N}^{\circ}$ & NP & -ar/ -en & & $\begin{array}{l}\text { SN (ref. } \\
\text { objeto) }\end{array}$ & & Ref. \\
\hline 2.1 . & tatuŕ & -en & -ḿ́i & & & AUD.02.09 \\
\hline 2.2 . & bantoŕ & -en & -ḿi & baikar & & B.44.16 \\
\hline 2.3 . & tikirsbalauŕ & -ar & -ḿi & ban & ḿi & GI.20.02 \\
\hline
\end{tabular}


Tabla 3: SN-te + -míi / -nai

\begin{tabular}{|l|l|l|l|l|}
\hline $\mathrm{N}^{\circ}$ & $\mathrm{SN}$ & - te & -ḿi / -nai & Ref. \\
\hline 3.1. & śalaiaŕkis & -te & -nai ${ }^{15}$ & T.07.01 \\
\hline 3.2 & boŕotenbo & -te & -nin $^{16}$ & TE.02.287 \\
\hline
\end{tabular}

Tabla 4: SN + SV + -míi

\begin{tabular}{|l|l|l|l|l|l|}
\hline $\mathrm{N}^{\circ}$ & $\mathrm{NP}$ & - te & ¿Verbos? & & Ref. \\
\hline 4.1. & basibalkar & & ḿbaŕ & ḿi & V.01.01 \\
\hline 4.2. & neŕsetikan & $-\mathbf{t}(\mathbf{e})$ & ekiar & ḿi & CS.16.01 \\
\hline 4.3. & & & iunsir & ḿi & CS.21.07 \\
\hline
\end{tabular}

La tabla 1 recoge los distintos contextos de aparición de -míi en aposición directa a un sintagma nominal, ya sea referido a un nombre personal (NP) $\left(n^{\circ} .1 .1\right)$, ya sea a un apelativo que parece coincidir con la mención del objeto inscrito ${ }^{17}(1.2-1.5)$. En este segundo caso, la fórmula puede verse, a su vez, ampliada con la adición de un posible determinante entre el sintagma nominal (SN) y $(\mathrm{CN})$ ante el $\mathrm{SN}$, ya sea expresado como $\mathrm{SN}-\mathrm{en}\left(\mathrm{n}^{\circ}\right.$. 1.4) o como un $\mathrm{SN}$ sin marca sufijal ( $\mathrm{n}^{\circ}$. 1.5), en simple relación de yuxtaposición paratáctica. Estos ejemplos encajan perfectamente en una interpretación como inscripciones parlantes, especialmente aquellos casos en los que -ḿi determina al nombre del objeto: así, la fórmula ampliada que encontramos en 1.4, sería interpretable como «yo soy el seltar de Iltirbikis». Los casos en los que -ḿi determina a un NP plantean algunas dudas más desde un punto de vista pragmático: cuando este esquema aparece en tumbas — su contexto de aparición más común, como es el caso de $\mathrm{n}^{\circ}$. 1.1, «yo soy Tarbanikor»—- sería fácil interpretar que se identifica el monumento funerario con el difunto - recuérdese además la existencia de estelas antropomorfas en el mundo ibérico-; sin embargo, cuando la inscripción se halla en un vaso, la iden-

15 Téngase en cuenta que la lectura del texto es dudosa (tal vez sea preferible -ian).

${ }^{16}$ La propuesta de segmentar NP-te+nin y equiparar -nin con el elemento -ḿi se debe a Orduña 2009, pp. 507-508.

17 Puede encontrarse una síntesis sobre la interpretación de estos sustantivos en Moncunill 2017. Cf. supra nota 8 para las inscripciones con nombres de vasos en griego y en etrusco.

${ }_{18}$ Sobre la interpretación del elemento -ban véase Moncunill y Velaza 2019, p. 132. 
tificación del recipiente con el poseedor resulta menos convincente ${ }^{19}$. Agostiniani (1982, p. 186), quien identifica este mismo esquema en etrusco, no descarta que esta sea, con todo, la interpretación correcta, aunque no excluye tampoco que pueda tratarse de una expresión de tipo elíptico en la que deba sobreentenderse un verbo, así por ejemplo «a mí me ha dado / hecho... tal persona». En el caso del ibérico, existiría todavía otra interpretación alternativa: que la anteposición del NP a -ḿi debiera interpretarse como una relación de $\mathrm{CN}+\mathrm{SN}$, antes que como dos $\mathrm{SN}$ en simple relación de aposición. Fijémonos, así, en el ejemplo que nos proporcionan dos grafitos de Ensérune, escritos en dos vasos distintos pero por una misma mano: i]skeŕbinḿrḿi[ (HER.02.044) e i]skeŕbinḿn (HER.02.043). En el primer caso, la fórmula es del tipo NP-ar-ḿi, mientras que la segunda es del tipo NP-ḿi, pero, sin embargo, las dos inscripciones, practicadas no solo en el mismo tipo de vaso sino con el mismo ductus y exactamente con la misma disposición, parecen ser equivalentes desde un punto de vista pragmático. Las dos, por consiguiente, serían interpretables como «yo soy de Iskerbin».

En la tabla 2 recogemos aquellos casos en los que -ńi va precedido por un $\mathrm{CN}$, siempre un NP, que es interpretable como el poseedor del objeto. Esta fórmula puede verse también ampliada con la mención explícita, a continuación, del nombre del vaso (cf. $\mathrm{n}^{\circ}$. 2.2, una estructura prácticamente equivalente a 1.4, pero con una alteración del orden) o con una forma probablemente de tipo pronominal, referida igualmente al recipiente $\left(\mathrm{n}^{\circ} .2 .3\right)$. De nuevo, estos ejemplos son perfectamente analizables desde la perspectiva de los objetos parlantes, respectivamente: «yo soy de Tatur», «yo soy de Bantor el baikar», "yo soy de Tikirsbalaur, este soy yo».

Las tablas 3 y 4 aportan, en cambio, una perspectiva distinta y complementaria sobre la cuestión, ya que implican estructuras de tipo verbal. La tabla 3 presenta, a pesar de todo, algunas dificultades interpretativas, no solo porque los ejemplos disponibles son muy escasos, limitándose de hecho a los dos que aquí recogemos, sino también porque la identificación del elemento -ḿi / -nai no es del todo segura, al diferir aquí de la notación habitual de este

19 Debe tenerse en cuenta, sin embargo, que algunos de estos grafitos vasculares con la estructura NP-ḿi proceden de tumbas (GI.10.15, HER.02.04), con lo que la identificación del objeto con el difunto sería igualmente posible. Otros casos proceden de hábitat (HER.02.009), pero la mayoría de las veces no disponemos de esta información (GI.15.45; HER.02.043, .06, $.255, .293$; TE.02.124a, .342; TE.06.05). 
segmento en escritura ibérica nororiental (-nai y -nin, respectivamente, en vez de -míi). Por consiguiente, es necesario tomar estos dos ejemplos y las conclusiones que de ellos se derivan con cautela. Si la identificación de -ḿi I -nai fuera, con todo, correcta, estos dos textos serían relevantes porque permitirían reconocer una estructura de tipo NP-te-X, en la que X suele coincidir estructuralmente con una forma verbal ${ }^{20}$. De ser así, la interpretación más inmediata de estos textos como inscripciones parlantes apuntaría más al uso del verbo copulativo que al del pronombre de primera persona. Sin embargo, el segundo caso ( $\mathrm{n}^{\circ}$ 3.2) merece un comentario más detallado, al contarse entre los escasos textos ibéricos para los que existe un posible texto equivalente en latín, en este caso el de una estampilla gemela portadora de la leyenda Protemus fecit ${ }^{21}$. En efecto, la adaptación del nombre personal Protemus al ibérico boŕotenbo es del todo factible, pero no parece, en cambio, probable que la estructura que sigue, para la que, como hemos dicho, apenas si existen paralelos en ibérico, sea una adaptación literal del texto latino, esto es de la forma verbal fecit, puesto que las marcas de autoría, de las que disponemos de múltiples muestras en ibérico, se expresan mediante la bien conocida fórmula NP-te+ekiar. Esto ha llevado a suponer que podríamos estar, en efecto, ante dos textos equivalentes, pero desde un punto de vista comunicativo y pragmático, y no, en cambio, ante una traducción literal (Estarán 2016, p. 344). Debemos contemplar, por lo tanto, la posibilidad de que el texto ibérico expresara la firma del artesano con una inscripción parlante del tipo «yo soy Protemus» o, más verosímilmente, «a mí (me hizo) Protemus», con omisión del verbo equivalente a fecit, en una estructura que sería equivalente, aunque bajo forma elíptica, a las que comentaremos a continuación para la tabla 4.

La última tabla $\left(\mathrm{n}^{\circ} 4\right)$ muestra ahora los contextos de aparición de -ḿi tras palabras que admiten una interpretación como formas verbales. Siguiendo con nuestro análisis de estos textos desde la perspectiva de los tituli loquentes, una interpretación plausible para estos casos sería interpretar que -ḿi ejerce aquí la función gramatical de $\mathrm{CD}$, en referencia al objeto inscrito: por consiguiente, la interpretación de $n^{\circ}$. 4.2 sería una marca de autoría del tipo «Nersetikan me

${ }^{20}$ Sobre la identificación del verbo en ibérico, Quintanilla 2005 y Velaza 2011.

${ }^{21}$ A propósito de esta cuestión, véase recientemente Estarán 2016, pp. 344-345, con la abundante bibliografía anterior. Nos parece convincente su propuesta de reivindicar los dos textos como equivalentes. 
hizo». Debe hacerse notar que, siguiendo con esta línea de interpretación, la coincidencia de la misma forma flexiva de -ḿi en función de caso «absolutivo» y de objeto sería coherente con una estructura de lengua ergativa, como se atribuye al ibérico (Orduña 2008, pp. 275-302; Luján 2010, pp. 289-301), puesto que en este caso sería esperable que el sujeto no agente y el objeto de un verbo transitivo presentaran la misma forma (Ferrer 2006, p. 150).

En cambio, en este contexto, una interpretación de -ḿi como verbo copulativo parece a priori más difícil, aunque, teniendo en cuenta nuestro conocimiento poco avanzado de la morfología verbal ibérica, tal vez no deberíamos descartar que pudiera tratarse de algún tipo de forma auxiliar. Otra posibilidad igualmente valorable sería, finalmente, interpretar ekiar como una forma nominal del verbo, tal y como proponen algunos autores (De Hoz 2001, pp. 353357 y 2011, pp. 296-313; Quintanilla 2005, p. 513; Orduña 2009, pp. 501-503), con lo que podríamos tener una estructura del tipo «yo soy la obra de / por...».

Hasta aquí hemos querido demostrar cómo el corpus de inscripciones ibéricas con el elemento -ḿi / -nai puede ser satisfactoriamente analizable asumiendo que pudiera tratarse de inscripciones parlantes. Cabe preguntarse ahora, sin embargo, si las otras interpretaciones que siguen considerándose como posibles (véase $\S$ II) sirven igualmente para explicar de forma coherente el corpus, planteando de este modo una alternativa de interpretación distinta.

En primer lugar, y atendiendo a la multiplicidad de palabras y contextos en los que -ḿi / -nai puede aparecer (significativamente tanto tras NP y apelativos como formas verbales), creemos que debe concluirse que no nos hallamos ante un mero sufijo, sino ante una palabra de tipo enclítico ${ }^{22}$. Esto explicaría, además, por qué existen una serie de casos en los que este segmento es separado del resto del texto mediante interpunción (CS.05.01; .11.01; GI.20.02; HER.02.053; .274; TE.02.124a). También parece relevante

22 Existen algunos ejemplos en los que ḿi- aparece en posición proclítica (p. ej. AUD.05.14, $.15, .34, .35, .36)$ pero no es posible determinar con claridad la segmentación de estas formas, ni excluir que se trate de un caso de homofonía con el elemento que ahora nos ocupa. Por otra parte, en algunos pocos casos ḿi podría aparecer también como texto único (p. ej. AUD.05.26, L.03.05, Z.09.12 o .13), aunque tampoco aquí es posible discernir con claridad si se trata del mismo elemento o si, por lo contrario, se trata de algún tipo de marca o abreviatura. En caso de tratarse del mismo elemento, quizás fuese un argumento en favor de interpretar la palabra como pronombre personal, mejor que como forma verbal, aunque cualquier suposición en este sentido es todavía muy prematura. 
en este sentido el hecho de que en unos pocos casos -ḿi pueda llevar su propia sufijación: así aśuneḿie (HER.02.045) o eŕate eŕokar ḿie (B.11.01).

En segundo lugar, las fórmulas examinadas no se limitan a la expresión de la propiedad, sino que, como hemos visto, sirven también para la expresión de la autoría, y probablemente para otros usos que por el momento nos resultan más difíciles de reconocer. De este modo, no es pertinente considerar, como proponía Untermann, que estemos ante una mera «partícula posesiva», o una palabra restringida a la expresión de la posesión, sino a una forma que permite un uso expresivo mucho más amplio y diverso.

En cuanto a la posibilidad de que -ḿi / -nai pueda esconder un demostrativo o un deíctico, lo cierto es que esta interpretación podría aplicarse también a la mayoría de los casos analizables, aunque funcionaría peor por lo menos en dos ocasiones: cuando la palabra se encuentra en aposición directa a un NP, especialmente en inscripciones funerarias, o cuando se encuentra tras palabras que admiten una interpretación precisamente también como demostrativos, en una construcción que resultaría, por consiguiente, redundante. Sin embargo, el argumento principal por el que no nos inclinamos por esta interpretación no es tanto de tipo lingüístico sino tipológico: como hemos visto, esta palabra se repite en numerosas inscripciones configurando una serie de estructuras repetitivas y recurrentes, claramente de tipo formular, y los modelos epigráficos que encontramos en las epigrafías coetáneas a la ibérica no ofrecen paralelos para una estructura de este tipo formada con demostrativos, mientras que sí ofrecen, en cambio, numerosísimos casos de estructuras similares bajo forma de inscripciones parlantes.

\section{El corpus de las inscripciones en -mí / -nai: soportes, cronología y distribución geográfica}

Tanto el ya mencionado trabajo de M. Burzachechi sobre las inscripciones parlantes en Grecia como el de L. Agostiniani sobre la adopción de esta práctica en Italia coinciden en la identificación de las principales características de este hábito: se trata, en primer lugar, de una práctica documentada ya en las inscripciones más arcaicas, y que se intensifica a lo largo de los primeros siglos de desarrollo de la cultura escrita. En el caso de Grecia, los testimonios más tempranos podrían datar ya del s. VIII a. C., y el momento de máxima difusión se producirá entre los siglos VI-V a. C. Llama la atención también la amplísima variedad de funciones y soportes empleados: entre los objetos 
más antiguos destacan los vasos, algunos de ellos de tipo votivo, así como las piedras sepulcrales; pero la tradición de dar voz a las inscripciones acabará empleándose también profusamente en las firmas de artesanos, y no faltarán ejemplos de tipología muy heterogénea, como pesos y monedas, utensilios para tejer, inscripciones parietales, bloques de piedra, estatuas, etc. A partir del s. V a. C. en adelante, sin embargo, este uso va progresivamente disminuyendo en el mundo helénico, y se restringe especialmente a la epigrafía sepulcral; con todo, y aunque con menor intensidad, debemos recordar, como hemos ya mencionado, que los ejemplos de inscripciones parlantes llegan hasta las postrimerías de la antigüedad e incluso más allá.

Las más antiguas inscripciones ibéricas interpretables como tituli loquentes coinciden también con el primer horizonte escrito en esta cultura, y, al igual que en el mundo griego, la mayoría se halla en vasos cerámicos, aunque, como veremos, esta manifestación podrá adoptar también una gran multiplicidad de formas. Los primeros ejemplares disponibles se remontan por lo menos al s. IV a. C. y muestran una clara influencia del mundo colonial griego: debemos mencionar, en primer lugar, una serie de grafitos sobre cerámica ática que se concentran en los yacimientos de Empúries (GI.10.15, escrito precisamente en caracteres griegos), Ullastret (GI.15.45 y .25$)^{23}$ y especialmente Ensérune (HER.02.015, .026, .036, .037, .059), donde esta fórmula gozará de gran vitalidad también durante los dos siglos siguientes. Tal como es habitual en este tipo de cerámica, las inscripciones suelen hallarse en el pie del recipiente, con la salvedad de algunos vasos de Ensérune conocidos como «canthares à pouciers», que pueden portarlas de forma más visible en las asas. Precisamente estos recipientes son significativos del uso primigenio que pudieron tener estos grafitos, ya que se trata de vasos especialmente empleados para usos funerarios (Laurens y Schwaller 1987, p. 389). De hecho, tomados en su conjunto, los posibles tituli loquentes ibéricos sobre cerámica ática proceden en su mayoría de necrópolis ${ }^{24}$, con lo que estas

${ }^{23}$ La identificación del elemento -ḿi en estas inscripciones no es, sin embargo, segura. Su lectura es: J+baŕkabiuŕti[ (GI.14.45) y otami[ (GI.15.25). Todavía más dudosa, aunque no descartable, es su aparición en agitigem (GI.15.10) o J+tárui (GI.15.46).

${ }^{24}$ Este es el caso de GI.10.15, en Empúries, y de HER.02.015, .026, .036, .037, .059, en Ensérune. Los grafitos de Ullastret proceden, en cambio, del poblado, aunque su contexto exacto de hallazgo es desconocido. 
inscripciones, aun encajando en la estructura típica de la fórmula de propiedad «yo soy de X», deben ser puestos en relación con los ritos de la muerte.

En este primer periodo debemos situar también otras inscripciones que dan una dimensión distinta al posible uso de los tituli loquentes en el ámbito ibérico: algunos plomos de contenido comercial de La Serreta, en el área contestana, con textos en escritura grecoibérica (A.04.01a y .02). El más completo de ellos (A.04.01) puede ser interpretado como una carta opistógrafa escrita por dos manos distintas ${ }^{25}$; una vez completado el segundo texto, seguramente la respuesta al primero, el documento fue plegado y se añadió el nombre de su propietario en el exterior, sakaŕiskeŕ-ar-nai, probablemente «yo soy de Sakarisker». Sería este un uso peculiar de una inscripción parlante, que encontramos de nuevo en uno de los plomos de Pech Maho, ya en el siglo III a. C. (AUD.05.38), donde el destinatario o emisor de otra misiva comercial es expresado según una estructura parecida, leisir-en-ḿi «yo soy de Leisir»; por último, este mismo uso podría darse también en otro documento similar de Tivissa (T.07.01), donde śalaiaŕkis-te-nai (de ser esta la lectura correcta) podría ser la indicación, de nuevo, del destinatario o remitente, esta vez con una estructura tal vez interpretable como «Salaiarkis me (hizo) / me (escribió)». No es imposible que otros plomos contuvieran estructuras similares (cf. especialmente V.13.04, atribuido a Pico de los Ajos, Yátova) aunque la segmentación y análisis lingüístico de estos textos, a menudo de una notable extensión y complejidad sintáctica, resulta no pocas veces opaca (así, V.13.02 también de Pico de los Ajos o V.07.02, de los Villares, V.07.02, ambos probablemente de los ss. II-I a. C.).

A partir de finales del IV y especialmente durante el siglo III a. C., el uso de las inscripciones redactadas mediante el uso de -ḿi /-nai se consolida, y va propagándose por el territorio, al mismo tiempo que lo hace la práctica de la escritura. El uso funerario de esta tradición seguirá vigente en esta época, tal y como lo muestran algunos grafitos de Ensérune sobre campaniense, procedentes igualmente de la necrópolis (HER.02.027, .045), o una excepcional cista inscrita de Pech Maho datable de la primera mitad del s. III a. C. y que ha sido interpretada como la tumba de un personaje significado del oppidum (AUD.05.01). De este mismo siglo cabe recordar asimismo los plomos

\footnotetext{
${ }^{25}$ Para los plomos ibéricos interpretables como cartas, véase recientemente Simón 2019.
} 
hallados en la necrópolis de Orlell, ya que por lo menos uno de ellos podría incluirse también en el corpus de las inscripciones parlantes (CS.21.07).

Los hallazgos en necrópolis incluyen además una taza umbilicada procedente de una tumba en El Turó dels Dos Pins, Cabrera de Mar, con un grafito también de esta época grabado en la pared externa (B.44.16), bantoŕenmíibaikar, donde el término baikar ${ }^{26}$ apunta, ahora, a un uso religioso o ritual, interpretación también pertinente para un pequeño vaso recientemente hallado en Vilademuls (GI.07.07) con el texto J+tibaikarḿi datable entre la segunda mitad del siglo IV a. C. y finales del siglo III a. $\mathrm{C}^{27}$. El uso sagrado de estas posibles inscripciones parlantes queda asimismo bien reflejado en otra pieza un tanto más tardía (ante s. II a. C.) a juzgar por su paleografía, la denominada «jarrita de la Joncosa» (B.11.01); esta reviste un carácter excepcional tanto por su tipología — una jarrita inscrita ante cocturam en la pared externa y que presenta una de las dos asas claramente torcidas antes de su amortización - como por las características y extensión del texto - ca. 350 signos en 10 líneas, con un estilo claramente formular en el que -ḿi aparece constantemente repetido-. También podríamos considerar dentro del grupo de la epigrafía religiosa algunas inscripciones rupestres de la Cerdanya, aunque, si bien es verdad que la estructura NP-ḿi puede ser identificada un par de veces (GI.02.03 y tal vez también PYO.07.10), el contexto invitaría a entender estos casos como la firma de los peregrinos para dejar constancia de su paso por los santuarios de alta montaña antes que como textos parlantes propiamente dichos.

Mención aparte, aunque tal vez tampoco lejos del ámbito cultual, merece también un grupo de vasos de cerámica pintada de El Tossal de Sant Miquel de Llíria (V.06.008, .020, .028). De forma genérica estas piezas laboriosamente decoradas, donde las inscripciones se combinan con complejas escenas iconográficas, han sido interpretadas como obras de encargo de las elites locales con una finalidad de autorrepresentación a la vez que para su intervención en las ceremonias religiosas, a juzgar por la aparición de estas piezas puntualmente también en santuarios ${ }^{28}$.

26 Véase Moncunill y Velaza 2019, p. 123.

${ }^{27}$ Ferrer y Sánchez 2018.

${ }^{28}$ Para los contextos de aparición de estos vasos, Bonet 2013. 
En paralelo con el ámbito funerario y religioso, toman especial relevancia desde el s. III los grafitos en contextos de hábitat, interpretados a menudo, de forma genérica, como grafitos de propiedad. Se hallan, por ejemplo, sobre utensilios para tejer e hilar, esto es pesas de telar (tal vez GI.10.14) o, especialmente, fusayolas (GI.13.07, GI.20.02, Z.09.06) —una práctica que se documentará también con posterioridad en la Galia, tanto en latín como en la lengua local, como hemos comentado más arriba-, y, sobre todo, en vasos cerámicos. Por otro lado, en esta época prosperan también los textos en relación con la actividad comercial, tal como hemos destacado ya a propósito de las tablillas de plomo.

Las inscripciones de propiedad ${ }^{29}$ sobre distintos tipos de vasos cerámicos se documentan ya en Ensérune desde finales del s. IV o principios del s. III a. C. (HER.02.009), pero los ejemplos se multiplican en los dos siglos siguientes, ya sea sobre cerámica campaniense (HER.02.043, .044, .053, .061, .173) o gris (HER.02.236, .248, .249). Progresivamente estos vasos inscritos empezarán a hallarse repartidos también por todo el territorio, en un primer momento en la zona norte y en la costa - contamos con casos en Pech Maho (AUD.05.08), Elne (PYO.02.09 y .26) y en área layetana, en las actuales comarcas del Vallès y el Maresme (B.29.05; B.44.19) - ; y, ya en época romana, también en el interior - así en Can Sotaterra (Solsona), Lleida, El Castelillo (Alloza), El Palomar (Oliete), Azaila, La Cabañeta (El Burgo de Ebro) o Botorrita.

A pesar de la notable abundancia de documentos de este tipo, en realidad es difícil otorgarles una funcionalidad específica, puesto que su lugar preciso de procedencia o el uso del espacio en el que se ubicaban nos son a menudo desconocidos. La presencia de estos grafitos, por ejemplo, no solo sobre vajilla de mesa sino en un número significativo de jarras (HER.02.254, $.274, .292, .294$, PYO.02.26, TE.05.01, Z.11.12), podría hacer pensar en contextos simposíacos y de comensalidad, pero tampoco es descartable que algunos de ellos tuvieran su lugar en santuarios y que deban ser entendidos también como ofrendas cultuales. En cualquier caso, nos parece formalmente destacable el hecho de que la gran mayoría de estas inscripciones no suelen encontrarse ocultas bajo el pie del vaso — como es común, por ejemplo, con las marcas e inscripciones de tipo comercial—, sino que aparecen

29 Para una síntesis sobre las inscripciones de propiedad en Etruria, algunas de ellas bajo forma de tituli loquentes, véase Becker 2010. 
en un lugar destacable, normalmente en la pared externa del recipiente, resultando así legibles cuando este se encuentra en reposo. Este hecho sugiere que debía de tratarse no tanto de un uso meramente utilitario de la escritura, sino de una práctica con una dimensión representativa y estilística, un factor que encajaría bien con la interpretación de estos textos como inscripciones parlantes.

Como señalábamos más arriba, algunas de las inscripciones de nuestro corpus aparecen, a su vez, en soportes y contextos en relación con la actividad mercantil y artesanal. De ello dejan constancia una serie de ánforas esgrafiadas en el dorso o en el cuello, en la misma Ensérune (HER.02.333, .325), y con especial intensidad en la vecina Pech Maho (AUD.05.11, .13, .17, .25, todos ellos hallados en barrio con actividad artesanal); o, ya en los s. II-I a. C., también en El Palomar, Oliete (TE.05.09; TE.02.342), y tal vez en Tarragona (T.11.08). Son relativamente habituales asimismo las firmas de artesano generalmente ante cocturam en soportes cuya elaboración comporta una determinada pericia técnica: algunos de los ejemplos se hallan en dolia de grandes dimensiones (AUD.02.09), vasos como los kalathoi (B.20.16; B.46.01) u otros objetos singulares (CS.16.01). Por último, y todavía dentro del campo de la economía, resulta remarcable una leyenda en una dracma de imitación emporitana (datable entre 218 a. C. y ca. 180 a. C.) con el texto iltiŕtaśalirnai, que es posible interpretar, desde la perspectiva de las inscripciones parlantes como «yo soy el śaliŕ de Ildirda» ${ }^{30}$.

Finalmente, el grupo más reciente de inscripciones del corpus son las estelas funerarias, que de forma genérica suelen ser datadas entre los s. II-I a. C. y en las que es posible observar una progresiva influencia del hábito epigráfico latino. Algunas de ellas, sin embargo, enlazan todavía con la tradición indígena, lo que es perceptible especialmente a través del lenguaje iconográfico, que convive algunas veces con el texto, así como con la factura y la facies misma de la inscripción $^{31}$. En esta misma línea creemos que hay que interpretar una veintena de estelas con posibles tituli loquentes ${ }^{32}$, esto es como una práctica que traslada

${ }^{30}$ Existen paralelos en griego y élimo para monedas con inscripciones parlantes (Burzachechi 1962, p. 40; Agostiniani 1982, p. 166, nº 648 y p. 271).

${ }^{31}$ Para una visión diacrónica y evolutiva de este hábito en función de la relación entre texto e iconografía, véase Velaza 2017.

${ }^{32}$ Estas inscripciones son: B.37.02, Barcelona; B.41.02 y .03, Badalona; HU.02.01, El Pilaret, Fraga; TE.18.01, Mas de Barberán; TE.19.01, .02 y .03, Nogueruelas Iglesuela del 
la tradición antigua de enterrar a los muertos con vasos parlantes, tal como hemos visto en las primeras inscripciones parlantes ibéricas, a un nuevo modelo epigráfico, el de las estelas, tomado de la tradición romana. En estos soportes, el formulario propio de los tituli loquentes se irá abandonando poco a poco y será sustituido por fórmulas claramente romanas, como son la filiación, la edad del difunto $y$, en ocasiones, fórmulas funerarias como aŕe take.

Para resumir toda la información de esta sección, podemos concluir que el uso y funcionalidad de las inscripciones con la palabra -ḿi son muy variados, tal y como, de hecho, ocurre en el mundo itálico y helénico. Sin embargo, existen algunos elementos que toman una especial relevancia: en primer lugar, es destacable la alta cronología de las primeras inscripciones, que coincide prácticamente con los orígenes de la escritura en el mundo ibérico, y su aparición en áreas en contacto directo con el mundo colonial griego (Ensérune, Empúries y la Contestania); destaca también la preponderancia, en los orígenes de esta práctica, de la epigrafía sepulcral y su rápida propagación a otros ámbitos: el comercial y artesanal, votivo, y la expresión de la propiedad, especialmente en contextos tal vez simposíacos.

6. Reflexiones finales: modelos exógenos de los tituli loquentes ibéricos y consecuencias para la literacy

Como se ha expuesto a lo largo del artículo, las inscripciones ibéricas con el elemento -ḿi / -nai configuran un corpus rico e internamente coherente, en el que es posible discernir una serie de estructuras cuyo análisis lingüístico (cf. $\S \mathrm{IV}$ ) es plenamente compatible con inscripciones de tipo loquens, ya sea entendiendo -ḿi / -nai como el pronombre personal de primera persona ('yo' / 'me', para el que cabría recordar la forma vasca ni), ya sea considerándolo como la primera persona del verbo copulativo ('soy', tal vez relacionable con el vasco naiz).

Por otra parte, el hecho de que estas estructuras se documenten con gran asiduidad — se trata, de hecho, de uno de los esquemas más repetidos dentro

Cid; CS.01.02, Canet lo Roig; CS.04.01, Sant Mateu del Maestrat; CS.05.01, Mas Carbó de Dalt, Benassal; CS.08.01, .02 y .03, Alcalà de Xivert; CS.10.01, Les Emerites de Bell-1loc; CS.11.01. El Bordissal, Cabanes; CS.17.01, Algímia d'Almonesir; V.01.01, Sinarcas; V.04.10, .14 y .45, Sagunto; X.01.01, Caglari. 
del corpus ibérico-, sugiere que nos hallamos ante algún tipo de expresión estereotipada y formular, para la que, atendiendo también a las características cronológicas y funcionales del conjunto, el mejor paralelo existente es indiscutiblemente el de los tituli loquentes.

La identificación del modelo concreto del cual la epigrafía ibérica hubo tomado dicha tipología es una cuestión compleja, pero la influencia griega parece ser el candidato mejor situado, no solo porque el uso de este tipo de inscripciones en griego está bien documentado en la península ibérica desde el s. VI a. C., sino porque la influencia del contexto colonial jonio en el desarrollo de las primeras prácticas escriturarias ibéricas, dentro de las que se inscriben las más tempranas inscripciones en -ḿi / -nai, es, como hemos visto, del todo manifiesta: recuérdese, así, la relativamente alta cronología de estos textos (s. IV a. C.), su lugar de procedencia cerca de los enclaves coloniales, los soportes empleados (cerámicas áticas y laminillas de plomo), e incluso la elección ocasional del alfabeto griego como sistema de escritura. Por lo demás, tampoco debemos olvidar, tal y como se ha descrito en el trabajo, que la adopción de tituli loquentes en las distintas lenguas locales de Italia obedece claramente a la importación de un modelo heleno, tal y como parece producirse también en la Galia. Así, sin olvidar tampoco el potencial papel que hubieran podido ejercer para la vitalidad de este hábito en yacimientos como Ensérune el contacto con otros pueblos, en especial los etruscos, la amplia difusión de esta costumbre en el mundo ibérico parece apuntar, como decíamos, a los intensos contactos comerciales y culturales con el mundo helénico como foco primordial de propagación.

El análisis funcional de este conjunto de inscripciones aporta también algunos elementos de reflexión interesantes sobre la adopción y desarrollo de la escritura en el mundo ibérico y sobre los usos concretos de esta práctica a lo largo del tiempo. Las inscripciones ibéricas más antiguas datables por el soporte o el contexto arqueológico son un muy reducido grupo de esgrafiados breves sobre cerámica ática datables hacia finales del s. V a. C. y genéricamente interpretados como marcas de propiedad. Aunque poco se sabe de la funcionalidad concreta de estos grafitos, han sido habitualmente puestos en relación con un uso utilitario de la escritura en el contexto del desarrollo de la actividad comercial a raíz del contacto de los pueblos indígenas con mercantes griegos. Los más antiguos tituli loquentes ibéricos, por poco posteriores a estos primeros grafitos, abren una perspectiva nueva sobre esta cuestión: en primer lugar, porque entre los usos primigenios de este hábito no solo 
aparece el contexto comercial, sino también el funerario, lo que nos obliga a ampliar nuestra concepción sobre las primeras aplicaciones y funciones de la escritura en el mundo ibérico. En segundo lugar, resulta también interesante para valorar la propagación y consolidación de la literacy ibérica el aumento de tituli loquentes en los ss. III y II a. C. y su uso en el ámbito religioso y cultual, así como la abundancia de vasos con inscripciones de propiedad en los que el texto ocupará un espacio significativo del soporte, otorgándole así un valor que va más allá del puramente funcional. Estas prácticas ponen, en definitiva, de manifiesto la transmisión de determinados recursos estéticos y estilísticos al mismo tiempo que a los distintos pueblos ibéricos les llegaba el conocimiento mismo de la escritura, y evidencian la necesidad de insertar el fenómeno epigráfico ibérico en el cuadro general de la epigrafía paleoeuropea y su propia koiné expresiva.

\section{BIBLIOGRAFÍA}

Abélanet, J. (1997): «Les graffiti gallo-romains de Peyrestortes», Bulletin de l'Association archéologique des Pyrénées Orientales 12, pp. 75-85.

Agostiniani, L. (1982): Le iscrizioni parlanti dell'Italia Antica, Florencia.

BDH: Banco de Datos Hesperia, URL: <http://hesperia.ucm.es/> (13/09/2020).

Becker, H. (2010): «The Written Word and Proprietary Inscriptions in Etruria», Etruscan Studies 13, pp. 131-148.

Bellelli, V. y Benelli, E. (2009) [2010]: «Un settore specializzato del lessico etrusco: una messa a punto sui nomi di vasi», Mediterranea 6, pp. 139-152.

Benucci F. y Foladore G. (2008): «Iscrizioni parlanti e iscrizioni interpellanti nell'epigrafia medievale padovana», Padua Working Papers in Linguistics 2, pp. 56-133.

Bonet, H. (2013): «Contextos arqueológicos de los textos ibéricos valencianos», PalHisp. 13, pp. 387-406.

Burzachechi, M. (1962): «Oggetti parlanti nelle epigrafi greche», Epigraphica 24, pp. 3-54.

Carraro, F. (2007): «The Speaking objects of Archaic Greece: Writing and Speech in the First Complete Alphabetic Documents», en Lomas, K. et al. (eds.), Literacy and the State in the Ancient Mediterranean, Londres, pp. 65-80.

Cinti, M. G. (2019): «Gli oggetti parlanti: le epigrafi greche e latine in prima persona», en Giaccardi, G. (ed.), Homo loquens: valori e veicoli della parola nel mondo antico e medievale, Alessandria 2019, pp. 55-80.

Claustres, G. (1958): «Les graffites gallo-romains de Peyrestortes (Pyrénées-Orientales)», Gallia 16 (1), pp. 41-81. 
Colonna, G. (1990): «Le iscrizioni votive etrusche», Scienze dell'Antichità 3-4, pp. 875-903.

Correa, J. A. (1999): «Las nasales en ibérico», en Villar, F. y Beltrán, F. (eds.), Pueblos, lenguas y escrituras en la Hispania prerromana, Salamanca, pp. 375-396.

Crawford, M. H. (ed.) (2011): Imagines Italicae. A corpus of Italic Inscriptions, Londres.

De Hoz, J. (2001): «Hacia una tipología del ibérico», en Villar, F. y Fernández, P. (eds.), Religión, lengua y cultura prerromanas de Hispania, Salamanca, pp. 335-362.

De Hoz, J. (2011): Historia lingüística de la península ibérica en la Antigüedad. II: El mundo ibérico prerromano y la indoeuropeización, Madrid.

De Hoz, M. P. (en prensa): «Particularidades del hábito epigráfico en las colonias jonias de España y Francia. Propuesta de interpretación», en Coltelloni-Trannoy, M. y Moncunill, N. (eds.), La culture de l'écrit en Méditerranée occidentale à travers les pratiques épigraphiques, París.

Estarán, M. J. (2016): Epigrafía bilingüe del Occidente romano. El latín y las lenguas locales en las inscripciones bilingües y mixtas, Zaragoza.

Ferrer, J. (2006): «Nova lectura de la inscripció ibèrica de la Joncosa (Jorba, Barcelona)», Veleia 23, pp. 129-170.

Ferrer. J. (2008): «Ibèric kaśtaun: un element característic del lèxic sobre torteres», Cypsela 17, pp. 253-271.

Ferrer. J. (2013): «ḿltunśor: Un nou model de segell ibèric procedent de Ca l'Estrada (Canovelles, Barcelona)», Saguntum 45, pp. 161-169.

Ferrer, J. y Sánchez, M. (2017): «L'enigma B'oïde al descobert: kaśtaum i baikar en sengles inscripcions ibèriques sobre una tortera i un vaset de Camps de l'Hospital (Vilademuls)», RAP 27, pp. 221-236.

Feugère, M. (2004): «L'instrumentum, support d'écrit», Gallia 61, pp. 53-65.

Gómez Moreno, M. (1945): «Digresiones ibéricas: escritura, lengua», BRAE 24, pp. 275-288.

IGEP: M. P. de Hoz, Inscripciones griegas de España y Portugal, Madrid (2014).

IGF: J.-C. Decourt, Inscriptions grecques de France, Lyon (2004).

ILTG: P. Wuilleumier, Inscriptions latines des Trois Gaules, París (1963).

Laurens, A.-F. y Schwaller, M. (1987): «Vases attiques importés sur l'oppidum d'Ensérune : essai d'approche anthropologique», en Rouillard, P. y VillanuevaPuig, M.-Ch. (eds.), Grecs et Ibères au IVe s. av. J.-C. Commerce et iconographie, Burdeos, pp. 385-395.

Lazzarini, M. L. (1976): «Le formule delle dediche votive nella Grecia arcaica», MAL 19, pp. 48-354.

Lazzarini, M. L. (1973-1974): «I nomi dei vasi greci nelle iscrizioni dei vasi stessi», Arch.Cl. 25-26, pp. 341-375. 
Luján, E. (2010): «Las inscripciones musivas ibéricas del valle medio del Ebro: una hipótesis lingüística», PalHisp. 10, pp. 291-298.

Maras, D. (2015): «Storie di dono: l'oggetto parlante si racconta», en Haack, M.L. (ed.), L'écriture et l'espace de la mort. Épigraphie et nécropoles à l'époque préromaine, Roma, pp. 239-251.

Michelena, L. (1961): «Comentarios en torno a la lengua ibérica», Zephyrus 12, 1961, pp. 5-23.

MLH III: J. Untermann, Monumenta Linguarum Hispanicarum III. Die iberischen Inschriften aus Spanien, Wiesbaden (1990).

Moncunill, N. (2007): Lèxic d'inscripcions ibèriques (1991-2006), Tesis Doctoral, Universitat de Barcelona.

Moncunill, N. (2017): «Nombres comunes en ibérico y su inserción dentro de la frase», PalHisp 17, pp. 141-156.

Moncunill, N. y Bénézet, J. (2018): «Les graffitis latins du Mas Sauvy (Villeneuvede-la-Raho, Pyrénées Orientales), Anuari de filologia. Antiqua et Mediaevalia 8, pp. 594-604.

Moncunill, N. y Francès, J. (2017): «Un nuevo cálato inscrito de Ca n’Oliver (Cerdanyola del Vallès, Barcelona)», Saguntum 49, pp. 61-69.

Moncunill, N. y Velaza, J. (2019): Monumenta Linguarum Hispanicarum V.2. Lexikon der iberischen Inschriften, Wiesbaden.

Norden, E. (1939): Aus altrömischen Priesterbüchern, Leipzig.

Orduña, E. (2005): Segmentación de textos ibéricos y distribución de los segmentos, Tesis Doctoral, Universidad Nacional de Educación a Distancia.

Orduña, E. (2008): «Ergatividad en ibérico», Emerita 76, pp. 275-302.

Orduña, E. (2009): «De nuevo sobre el sufijo -te», PalHisp. 9, pp. 501-514.

Orduña, E. (2017): «Ibérico (n)Yltun y el signo Y ¿un nuevo caso de rinoglotofilia?», PalHisp. 17, pp. 157-175.

Orduña, E. (2019): «The Vasco-Iberian Theory», en Sinner, A. G. y Velaza, J. (eds.), Palaeohispanic Languages and Epigraphies, Oxford, pp. 219-239.

Poccetti, P. (2009): «Paradigmi formulari votivi nelle tradizioni epicoriche dell'Italia antica», en Bodel, J. y Mika, K. (eds.), Dediche sacre nel mondo greco-romano. Diffusione, funzioni, tipologie. Atti del Colloquio (Roma, 2006), Roma, pp. 43-94.

Quintanilla, A. (1998): Estudios de fonología ibérica, Vitoria.

Quintanilla, A. (2005): «Palabras de contenido verbal en ibérico», PalHisp. 5, pp. 507-520. RIG I = Lejeune, M., Recueil des Inscriptions Gauloises. Textes gallo-grecs, París. Rodríguez Ramos, J. (2000): «Vocales y consonantes nasales en la lengua íbera», Faventia 22, pp. 25-37.

Rodríguez Ramos, J. (2004): Análisis de epigrafía íbera, Vitoria.

Rodríguez Ramos, J. (2005): «Introducció a l'estudi de les inscripcions ibèriques», Revista de la Fundació Privada Catalana per l'Arqueologia ibèrica 1, pp. 13-146. 
Siles, J. (1981): «Sobre el signo ibérico Y y los valores fonéticos que anota», Emerita 49, pp. 75-96.

Siles, J. (1985): Léxico de inscripciones ibéricas, Madrid.

Silgo, L. (1994): Léxico ibérico, Valencia.

Silgo, L. (2001): «La estela de Sinarcas y su leyenda epigráfica», Arse 35, pp. 13-24.

Silgo, L. (2005): «Lengua y epigrafía ibéricas», en Aparicio, J. et al. (eds.), La cultura ibérica. Síntesis histórica, pp. 217-241.

Simón, I. (2019): «Las cartas ibéricas sobre plomo», Analecta Papyrologica 31, pp. 95-126.

Steiner, D. (1993): «Pindar's Oggetti Parlanti», HSCPh 95, pp. 159-180.

Thüry, G. (1994): «Mehrdeutige erotische Kleininschriften», Bayerische Vorgeschichtsblätter 59, pp. 85-95.

Tovar, A. (1954): «Sobre el planteamiento del problema vasco-ibérico», Archivum 4, pp. 220-231.

Tovar, A. (1985): «El signo Y del ibérico y un descubrimiento de Michelena», en Melena, J. L. (ed.), Symbolae Ludovico Mitxelena septuagenario oblatae, Vitoria, pp. 463-468.

Untermann, J. (1984): «Der iberische Buchstabe Y. Versuch einer Zwischenbilanz», en Oroz, F. J. (ed.), Navicula Tubingensis, studia in honorem Antonii Tovar, Tubinga, pp. 377-387.

Untermann, J. (1998): «Comentario sobre una lámina de plomo con inscripción ibérica de la colección D. Ricardo Marsal, Madrid», Habis 29, pp. 7-21.

Valeri, V. (1993): «Las nasales ibéricas», en Untermann, J. y Villar, F. (eds.), Lengua y cultura en la Hispania prerromana, Salamanca, pp. 739-746.

Velaza, J. (2011): «Cuestiones de morfología verbal en ibérico», A Greek Man in the Iberian Street. Papers on Linguistics and Epigraphy in Honour of Javier de Hoz, Innsbruck, pp. 295-304.

Velaza, J. (2017): «Imagen y texto en la epigrafía funeraria ibérica», PalHisp. 17, pp. 235-248.

Velaza, J. (2019): «Iberian Writing and Language», en Sinner, A. G. y Velaza, J. (eds.), Palaeohispanic Languages and Epigraphies, Oxford, pp. 160-197.

Vidal, J. C. (2019): «Objectes que parlen: baikar, kaśtaun i seltar», RAP 29, pp. 91-120. Wachter, R. (2010): «The Origin of Epigrams on "Speaking Objects"», en Baumbach, M. et al. (eds.), Archaic and Classical Greek Epigram, Cambridge, pp. 250-260.

Fecha de recepción de la primera versión del artículo: 28/07/2020

Fecha de aceptación: 18/08/2020

Fecha de recepción de la versión definitiva: 13/09/2020 